\title{
Overwintering of Puccinia striiformis f. tritici on Winter Wheat at Varying Altitudes in Gansu and Qinghai Provinces
}

Lijie Ma, Xinyu Kong, Jiaxing Qiao, Fei An, and Xiaoping Hu, State Key Laboratory of Crop Stress Biology for Arid Areas, College of Plant Protection, Northwest A\&F University, Taicheng Road 3, Yangling 712100, China; and Xiangming Xu, East Malling Research, New Road, East Malling, ME19 6BJ, Kent, UK

\begin{abstract}
Ma, L. J., Kong, X. Y., Qiao, J. X., An, F., Hu, X. P., and Xu, X. M. 2016. Overwintering of Puccinia striiformis f. tritici on winter wheat at varying altitudes in Gansu and Qinghai Provinces Plant Dis. 100:1138-1145.

Stripe rust, caused by Puccinia striiformis f. tritici, is an important wheat disease in China. $P$. striiformis $\mathrm{f}$. sp. tritici overwintering and nonoverwintering regions based on the temperature were described elsewhere (Shi et al. 2005). The temperature limit for $P$. striiformis f. sp. tritici overwintering is derived from field observations. However, $P$. striiformis f. sp. tritici has recently been observed to overwinter at sites where overwintering is predicted to be unlikely. We studied $P$. striiformis $\mathrm{f}$. sp. tritici overwintering across several sites in regions close to or further away from the current P. striiformis f. sp. tritici "overwintering boundary" in China. Plants with $P$. striiformis f. sp. tritici symptoms and uredinia were tagged in late autumn and moved to the laboratory in early spring the following year for quantification of $P$. striiformis f. sp. tritici biomass via a quantitative reversetranscription polymerase chain reaction method and for assessment of $P$. striiformis f. sp. tritici symptoms and sporulation after incubation in a greenhouse. The molecular method detected $P$. striiformis f. sp. tritici in

leaves and sheath in most samples, much greater than the observed incidence of $P$. striiformis f. sp. tritici symptoms and sporulation after incubation. Thus, further refinement may been necessary to calibrate this molecular method in order to avoid overestimating $P$. striiformis f. sp. tritici overwintering potential. Active sporulation (hence, successful overwintering) was observed for all sites except one. Increasing altitude led to decreasing incidence of visible $P$. striiformis f. sp. tritici symptoms and sporulation; in addition to lower temperatures in high altitudes, wind chill may also explain this negative relationship between $P$. striiformis $\mathrm{f}$. sp. tritici overwinter potential and altitude. $P$. striiformis $\mathrm{f}$. $\mathrm{sp}$. tritici sporulation on plants subjected to different treatments (control, two oldest leaves, or all leaves removed) indicated that $P$. striiformis $\mathrm{f}$. sp. tritici overwinters in young green leaves as latent infection established in late autumn. The present study suggests that using only temperature to predict overwintering potential of $P$. striiformis f. sp. tritici at a given site is insufficient for mountainous regions.
\end{abstract}

Stripe rust (yellow rust), caused by Puccinia striiformis f. tritici Erikss., is a destructive disease on wheat worldwide (Chen 2005). China is the largest $P$. striiformis $\mathrm{f}$. sp. tritici epidemic region in the world (Li and Zeng 2002; Stubbs 1988), mostly in winter-wheatgrowing areas in northwestern, southwestern, and northern China (Wan et al. 2003). The P. striiformis f. sp. tritici annual cycle in China is usually divided into four stages: oversummering, autumn epidemics on seedlings, overwintering, and spring epidemic (Li and Zeng 2002). Crop loss is primarily determined by the severity of the spring epidemic, which is mainly influenced by the amount of overwintered inoculum and weather conditions in the spring (Gladders et al. 2007; Li and Zeng 2002; Sharma-Poudyal and Chen 2011). The amount of $P$. striiformis f. sp. tritici overwintered inoculum is usually estimated visually as incidence of plants with $P$. striiformis $\mathrm{f}$. $\mathrm{sp}$. tritici uredinia in the early spring. It can also be estimated by combining the severity of autumn epidemics and the effect of winter conditions on $P$. striiformis f. sp. tritici survival. Winter wheat growing in northwestern, southwestern, and northern China may be classified into three types (Li and Zeng 2002; Zeng and Luo 2008). First, all aboveground leaves died during the winter, mostly in high-latitude or high-altitude areas. Second, although some parts of leaves senesced during the winter, the plant remains green, mostly in low-latitude or low-altitude areas. Finally, wheat leaves

Present address of L. Ma: Erdos Ecological Environment of Career Academy, Ordos 017010, China.

Corresponding author: X. Hu; E-mail: xphu@nwsuaf.edu.cn

*The $\boldsymbol{e}$-Xtra logo stands for "electronic extra" and indicates that seven supplementary figures are published online.

Accepted for publication 17 December 2015.

http://dx.doi.org/10.1094/PDIS-09-15-1112-RE

(C) 2016 The American Phytopathological Society are still growing (albeit slowly) during the winter, mostly in southern China. Winter-wheat-growing areas in China have been divided into overwintering and nonoverwintering regions based on empirical field observations (Shen and Wang 1962; Shi et al. 2005) (Fig. 1). Recent field observations suggest that the overwintering boundary may have been gradually pushed toward the northwest (Pan et al. 2011; Yao et al. 2014), which is believed to result from climate changes in recent times (Fang et al. 2012).

To estimate the amount of overwintered inoculum, we also need to understand the potential of $P$. striiformis f. sp. tritici overwintering on different wheat tissues in order to estimate the severity of autumn epidemics. As an obligate parasite, $P$. striiformis $\mathrm{f}$. sp. tritici has to overwinter in living tissue (Li and Zeng 2002) and can survive as dormant mycelium as long as infected leaves remain alive during the winter (Li and Zeng 2002; Sharp and Hehn 1963). P. striiformis f. sp. tritici is believed to survive on newly infected leaves in autumn, which emerged prior to the onset of the winter (Li and Zeng 2002). $P$. striiformis $\mathrm{f}$. sp. tritici may remain latent in infected leaves for nearly 100 days as dormant mycelia or uredia (Burleigh 1965; Li and Zeng 2002). However, the exact wheat tissues (e.g., leaves with latent $P$. striiformis f. sp. tritici, leaves with uredinia, and sheath) on which $P$. striiformis f. sp. tritici could overwinter remain unclear, affecting the accuracy of autumn $P$. striiformis f. sp. tritici assessment for predicting $P$. striiformis $\mathrm{f}$. sp. tritici overwintering potential.

The objectives of this study were to (i) determine overwintering of $P$. striiformis f. sp. tritici in several regions in northwestern China, where the fungus previously was considered not to overwinter, and (ii) estimate the function of wheat tissues such as leaves and sheaths on overwintering of $P$. striiformis f. sp. tritici.

\section{Materials and Methods}

Sites and wheat varieties. Field experiments were conducted in two seasons (2012-13 and 2013-14) at 10 and 8 sites (fields) in Gansu and Qinghai Provinces, respectively (Fig. 1; Table 1). In each field, four varieties (Table 1) were sown within a single plot (10 by $20 \mathrm{~m}$ ), 
with each variety occupying $50 \mathrm{~m}^{2}$ (2.5 by $20 \mathrm{~m}$ ) (Supplementary Fig. S1). Across all sites, two common varieties were used: 'Xiaoyan 22' (XY22, low winter hardiness) and 'Xinong 979' (XN979, moderate winter hardiness). The other two varieties were from the local regions and, hence, may differ between sites. Within each site, two narrow strips $(0.15$ by $20 \mathrm{~m})$ of a susceptible variety ('Mingxian 169' [MX169], low winter hardiness) were planted. The MX169 plants were inoculated in early autumn to act as and inoculum source for other varieties to initiate autumn epidemics. At each site, a temperature logger (USB502; Applied Measurements Ltd.) was placed in the plot among plants approximately $5 \mathrm{~cm}$ above the ground to record temperature at hourly intervals.

Field inoculation of MX169 by $P$. striiformis f. sp. tritici. $P$. striiformis f. sp. tritici inoculum was initially multiplied in a controlled environment for use in the field inoculation. Twenty seeds of MX169 were sown in each pot (10 by $12 \mathrm{~cm})$, containing cow dung compost and soil $(1: 2, \mathrm{vol} / \mathrm{vol})$. When the first two leaves were fully expanded (8 to 10 days after sowing), seedlings were inoculated with fresh urediniospores of Chinese Yellow Rust (CYR) 32 (Li and Shang 1989). The inoculated seedlings were immediately placed in a dew chamber at 8 to $10^{\circ} \mathrm{C}$ in dark for $24 \mathrm{~h}$, then moved out to a greenhouse compartment (17 and $14^{\circ} \mathrm{C}$, day [10 h] and night [14 h], respectively). Fresh urediniospores were collected from these inoculated leaves with a clean finger-like tube and stored in a desiccator at $4{ }^{\circ} \mathrm{C}$.
In mid-October, MX169 plants at each site were inoculated with the above collected fresh urediniospores of $P$. striiformis f. sp. tritici CYR32. Seedlings were first sprayed with water to wet the leaves. Then, urediniospores were mixed with talcum powder $(1: 20$, $\mathrm{vol} / \mathrm{vol})$ in a glass test tube $(0.5 \mathrm{by} 12 \mathrm{~cm}, 15 \mathrm{ml})$, covered with three layers of cotton gauze, scattered over seedlings through gently tapping the test tube (Li and Shang 1989). Inoculated seedlings were immediately covered with black polythene to ensure successful infection; the cover was removed after $24 \mathrm{~h}$.

$P$. striiformis f. sp. tritici detection on tagged plants. In late November, a number of plants with visible $P$. striiformis $\mathrm{f}$. sp. tritici symptoms (with urediniospores) - 30 in 2012 and 36 in 2013 of each variety at each site-were randomly selected and tagged with red string. In November 2013, the 36 tagged plants were divided into three groups (12 in each group): (i) the two outmost leaves (with $P$. striiformis f. sp. tritici symptoms) were cut off (the remaining green leaves did not show $P$. striiformis f. sp. tritici symptoms) (young leaf only [YLO]), (ii) all leaves (excluding sheath) were cut off (sheath only [SO]), and (iii) no treatment applied (whole plant [WP]) (Supplementary Fig. S2).

In mid-March of the following year, all tagged plants at all sites were collected (dug up with their root systems; Supplementary Figs. S3 to S6). Each plant was divided into two parts of tillers: one stored into RNAlater Tissue Collection (AM7021; Ambion

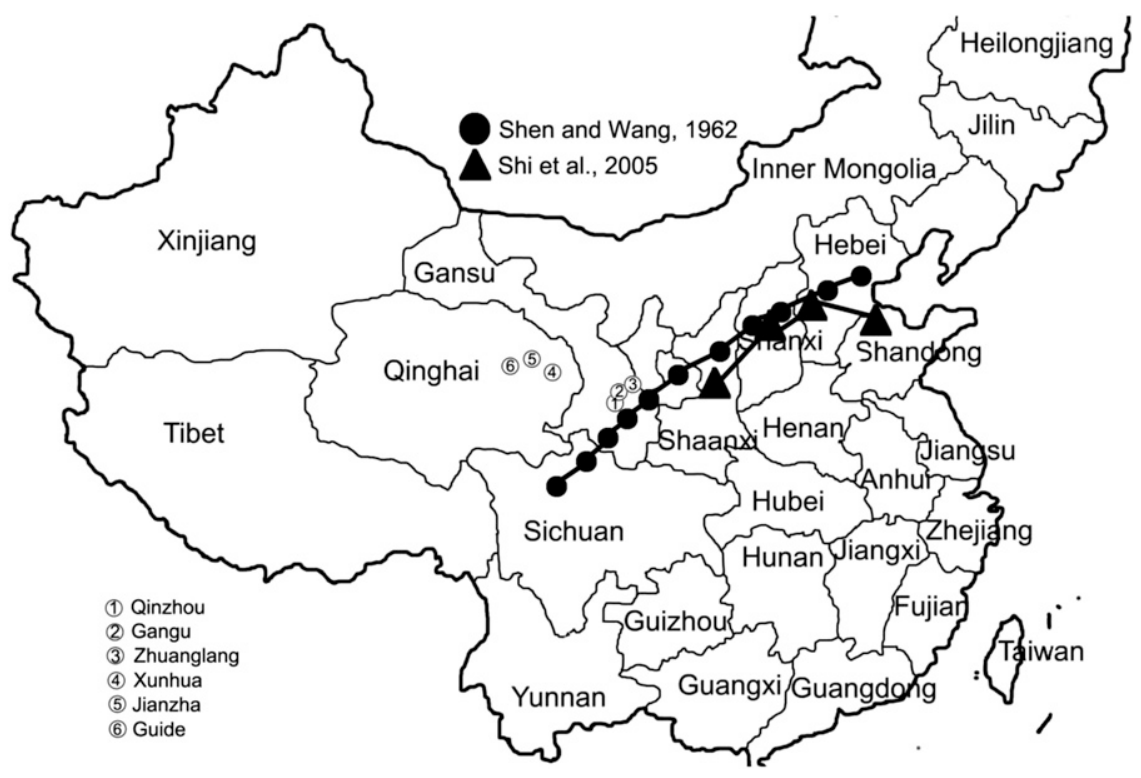

Fig. 1. Six locations north of the predicted geographical boundary of Puccinia striiformis f. tritici overwintering in China. Solid triangles and dots were overwintering boundaries given by Shen and Wang (1962) and Shi et al. (2005), respectively. P. striiformis f. sp. tritici can overwinter in areas south of the boundaries and not overwinter the north of the boundaries.

Table 1. Key information on field experiments of wheat stripe rust overwintering in Gansu and Qinghai Provinces, China in 2012-13 and 2013-14

\begin{tabular}{|c|c|c|c|}
\hline Site & Field location & Altitude (m) & Wheat varieties ${ }^{\mathrm{z}}$ \\
\hline \multicolumn{4}{|l|}{ Gansu Province } \\
\hline Qinzhou A & $\mathrm{E} 105^{\circ} 42^{\prime} 443^{\prime \prime}, \mathrm{N} 34^{\circ} 23^{\prime} 778^{\prime \prime}$ & 1,731 & $\begin{array}{l}\text { XY22 (1, l), XN979 (m, m), 01-314 (m, h), } \\
\text { LT91474 (h, h) }\end{array}$ \\
\hline Qinzhou B & $\mathrm{E} 105^{\circ} 42^{\prime} 379^{\prime \prime}, \mathrm{N} 34^{\circ} 24^{\prime} 294^{\prime \prime}$ & 1,644 & XY22, XN979, 01-314, LT91474 \\
\hline Qinzhou C & $\mathrm{E} 105^{\circ} 42^{\prime} 484^{\prime \prime}, \mathrm{N} 34^{\circ} 24^{\prime} 466^{\prime \prime}$ & 1,590 & XY22, XN979, 01-314, LT91474 \\
\hline Gangu A & $\mathrm{E} 105^{\circ} 16^{\prime} 623^{\prime \prime}, \mathrm{N} 34^{\circ} 38^{\prime} 366^{\prime \prime}$ & 2,090 & XY22, XN979, 01-314, TX46 (h, h) \\
\hline Gangu B & $\mathrm{E} 105^{\circ} 18^{\prime} 178^{\prime \prime}, \mathrm{N} 34^{\circ} 43^{\prime} 274^{\prime \prime}$ & 1,463 & XY22, XN979, 01-314, TX46 \\
\hline Zhuanglang A & $\mathrm{E} 106^{\circ} 12^{\prime} 004^{\prime \prime}, \mathrm{N} 35^{\circ} 18^{\prime} 655^{\prime \prime}$ & 1,974 & XY22, XN979, 06-11 (m, h), LT26 (h, h) \\
\hline Zhuanglang B & $\mathrm{E} 106^{\circ} 05^{\prime} 784^{\prime \prime}, \mathrm{N} 35^{\circ} 15^{\prime} 810^{\prime \prime}$ & 1,690 & XY22, XN979, 06-11, LT26 \\
\hline \multicolumn{4}{|l|}{ Qinghai Province } \\
\hline Guide & $\mathrm{E} 101^{\circ} 25^{\prime} 141^{\prime \prime}, \mathrm{N} 36^{\circ} 01^{\prime} 873^{\prime \prime}$ & 2,226 & XY22, XN979, LT15 (h, h), JN411 (h, m) \\
\hline Jianzha & $\mathrm{E} 101^{\circ} 55^{\prime} 775^{\prime \prime}, \mathrm{N} 36^{\circ} 03^{\prime} 165^{\prime \prime}$ & 2,099 & XY22, XN979, LT15, JN411 \\
\hline Xunhua & $\mathrm{E} 102^{\circ} 22^{\prime} 310^{\prime \prime}, \mathrm{N} 35^{\circ} 52^{\prime} 562^{\prime \prime}$ & 1,877 & XY22, XN979, LT15, JN411 \\
\hline
\end{tabular}

${ }_{\mathrm{z}}$ The first letter in parentheses indicates winter hardiness $(\mathrm{l}=\mathrm{low}, \mathrm{m}=$ moderate, and $\mathrm{h}=$ high $)$ and the second letter indicates resistance to Puccinia striiformis $\mathrm{f}$. tritici $(\mathrm{l}=$ low, $\mathrm{m}=$ moderate, and $\mathrm{h}=$ high $)$. 
Co.) for real-time quantitative reverse-transcription polymerase chain reaction (qRT-PCR) quantification of $P$. striiformis $\mathrm{f}$. sp. tritici, and the other potted into a pot $(10$ by $12 \mathrm{~cm})$ for incubation in a greenhouse compartment $\left(17\right.$ and $14^{\circ} \mathrm{C}$, photoperiod of 10 and $14 \mathrm{~h}$, respectively) for 2 weeks for $P$. striiformis f. sp. tritici assessment on overwintered green leaves. The visual $P$. striiformis $\mathrm{f}$. sp. tritici symptoms were classified into three types: (i) no P. striiformis f. sp. tritici symptom, (ii) initial symptom expression without sporulation, and (iii) sporulation. The $P$. striiformis f. sp. tritici symptoms were recorded every 3 days.

RNA extraction. For RNA quantification, 1,200 samples (30 seedlings of each variety $\times$ four varieties $\times 10$ sites) and 1,152 samples (36 each variety $\times$ four varieties $\times 8$ sites) were treated for 2012-13 and 2013-14, respectively. The samples were treated following manufacturer's instructions, with some modification. Samples were first taken out of the RNAlater solution (AM7021; Ambion Co.), soaked in tap water for 2 min to remove soil and RNAlater solution, and transferred to $75 \%$ alcohol for $10 \mathrm{~s}$ to further remove RNAlater solution. The sample was again soaked in sterile distilled water for $2 \mathrm{~min}$ to remove alcohol and residual RNAlater solution, and pressed onto a piece of sterile filter paper to dry. For the 2012-13 experiment, each plant was cut into two parts: one including all the leaves and the other with the sheath only. All samples were weighed, put into $2.0-\mu$ l centrifuge tubes, and stored at $-80^{\circ} \mathrm{C}$.

RNA was extracted using a previously published method (Ma et al. 2015). Briefly, wheat tissues of $100 \mathrm{mg}$ were ground into powder in liquid nitrogen and transferred into a $2.0-\mu l$ centrifuge tube for RNA extraction. cDNA was obtained through RT of RNA using PrimeScript RT Reagent Kit (Perfect Real Time DRR037A; TaKaRa) following the manufacturer's instructions. RNA was reverse transcribed at $37^{\circ} \mathrm{C}$ for $15 \mathrm{~min}$, followed by heating at $85^{\circ} \mathrm{C}$ for $5 \mathrm{~s}$.

Real-time qRT-PCR. RNA was quantified following a recently published method (Ma et al. 2015). Briefly, qRT-PCR was performed using an UltraSYBR Mixture kit (catalog number CW0957A; CWBIO). The primer pair of $P$. striiformis $\mathrm{f}$. sp. tritici elongation factor 1 (forward primer: 5'-TTC GCC GTC CGT GAT ATG AGA CAA- 3 ' and reverse primer: 5'-ATG CGT ATC ATG GTG GTG GAG TGA-3'; Yin et al. 2009) was used. Each reaction contained $12.5 \mu$ l of Ultra SYBR Mixture, $1.0 \mu \mathrm{l}$ of primer mix (containing $10 \mu \mathrm{M}$ each primer), $2 \mu \mathrm{l}$ of cDNA (100 ng of RNA), and RNase-free water up to $25 \mu l$. The amplification conditions were as follows: a denaturation step at $95^{\circ} \mathrm{C}$ for $3 \mathrm{~min}$; followed by 40 amplification cycles consisting of denaturation at $95^{\circ} \mathrm{C}$ for $30 \mathrm{~s}$, annealing at $60^{\circ} \mathrm{C}$ for $30 \mathrm{~s}$, and extension at $72^{\circ} \mathrm{C}$ for $30 \mathrm{~s}$ with an amplification melting curve at $95^{\circ} \mathrm{C}$ for $1 \mathrm{~min}$ and $55^{\circ} \mathrm{C}$ for $1 \mathrm{~min}$; followed by 81 cycles of $20 \mathrm{~s}$ from 55 to $95^{\circ} \mathrm{C}$ with a step of $0.5^{\circ} \mathrm{C}$. It was conducted on a real-time Thermal Cycler iQ5 (Bio-Rad). The iQ5 software 2.1 was used to estimate cycle threshold $(\mathrm{Cq})$ values and PCR efficiency at the default settings. For each sample, there were three technical replicates.

A standard curve was constructed to estimate RNA in terms of number of urediniospores. RNA was extracted from $10 \mathrm{mg}$ of fresh urediniospores and dissolved into $20 \mu \mathrm{l}$ of RNase-free water, giving an RNA concentration of $400 \mathrm{ng} / \mu \mathrm{l}$. Because of the constraint imposed by the transcription kit used, only $2.5 \mu$ l of RNA $(1,000 \mathrm{ng})$ can be reversely transcribed into $20 \mu \mathrm{l}$ of cDNA. In the quantification system, $2 \mu l$ of cDNA was added, which was equivalent to cDNA from $1.25 \times 10^{-1} \mathrm{mg}$ of urediniospores. This cDNA standard was serially diluted 10-fold using RNase-free water to obtain concentrations of $1.25 \times 10^{-1}, 1.25 \times 10^{-2}, 1.25 \times 10^{-3}, 1.25 \times 10^{-4}$, and $1.25 \times$ $10^{-5} \mathrm{mg}$ of urediniospores, with three replicates each. These standards were included in every qRT-PCR plate. To estimate the number of urediniospores per milligram, $1 \mathrm{mg}$ of urediniospores was diluted with $1 \mathrm{ml}$ of sterile distilled water, with two droplets of Tween 20 added to disperse the urediniospores. The number of urediniospores was counted under a microscope using a hemocytometer (Olympus BX51): there were $1.05 \times 10^{5}$ urediniospores $/ \mathrm{mg}$. Finally, a standard curve relating $\mathrm{Cq}$ values to the number of urediniospores was derived from the standards.

Data analysis. There were two types of data from the present experiments: $P$. striiformis $\mathrm{f}$. sp. tritici biomass on individual plants quantified by qRT-PCR as number of urediniospores, and number of plants with $P$. striiformis $\mathrm{f}$. sp. tritici detected, visible $P$. striiformis $\mathrm{f}$. sp. tritici symptoms, or $P$. striiformis $\mathrm{f}$. sp. tritici sporulation after incubation in the greenhouse. Mixed-model analysis was applied to the data with altitude (numerical variate), tissue type, and site (both as a factor) as fixed-effect variables. The present study focused on the effects of geographical locations (site, including altitude) for $P$. striiformis $\mathrm{f}$. sp. tritici overwintering and the plant tissue on which $P$. striiformis f. sp. tritici may overwinter. In addition, different varieties were used across the sites. Thus, variety, as well as its interaction with other factors was considered as a random-effect variable in the mixed-model analysis.

For a few samples in 2012-13, the estimated numbers of urediniospores were extremely large compared with other samples and, hence, they were replaced with the maximum values of the remaining samples. The urediniospore number estimated by the qRT-PCR was first ln-transformed to reduce heterogeneity before further statistical analysis. A linear mixed model was applied to the data, with altitude, location, and tissue type as fixed-effect variables and with variety as a random-effect variable (in 2012, individual plants were also treated as a random-effect factor). Only samples with the estimated number of urediniospores $\geq 0.5$ were included in the mixed-model analysis. Similar analysis was applied to the count data (i.e., number of plants with positive qRT-PCR $[\geq 0.5$ urediniospores]), $P$. striiformis $f$. sp. tritici symptoms, or $P$. striiformis f. sp. tritici sporulation, except that residual errors were assumed to follow a binomial distribution. Thus, generalized linear mixed models (GLMM) were applied to the count data. No $P$. striiformis $\mathrm{f}$. sp. tritici sporulation was observed on plants from the SO treatment at all sites in 2013-14 and, hence, this treatment was excluded from GLMM analysis. Pairwise comparison (based on least significant difference) was conducted only if mixed-model analysis showed statistical significance of the main effect of a treatment factor under consideration. In addition, a $\chi^{2}$ test was used to assess whether there were differential incidences of positive PCR tests on leaves and sheaths at each site for the 2012-13 data. All statistical analysis was carried out in Genstat (version 13; VSNI International Ltd.).

\section{Results}

Standard curves based on RNA (cDNA) were directly estimated by software in iQ5 (Supplementary Fig. S7). Coefficients of determination of the standard curves were greater than 0.99 in all quantification runs. Amplification efficiency for RNA (cDNA) ranged from 100.7 to $101.2 \%$.

Daily average temperature varied greatly among sites in the two study seasons (Fig. 2). Temperature during the winter was generally much lower in 2013-14 than in 2012-13 for all sites (Fig. 2). There were many days with average temperatures less than $-6^{\circ} \mathrm{C}$, particularly in 2013-14 at Zhuanglang B and Guide. The differences in daily average temperatures between sites were greater in the 2013-14 than in the 2012-13 season during the coldest period (from mid-December to mid-January; Fig. 2).

Incidence of disease determined through qRT-PCR. In early March 2013, there were plants with $P$. striiformis f. sp. tritici uredinia at Gangu B and Qinzhou C only. Plants after winter were still green at all sites, except two sites in Zhuanglang, where they were severely withered. In early spring 2014, there was no plant with $P$. striiformis f. sp. tritici uredinia in any sites. Plants after winter were withered in Guide.

Nearly all samples in 2012-13 had positive qRT-PCR results, except those from Gangu A and B and Qinzhou A (Table 2); even for these three sites, the overall incidence of $P$. striiformis $\mathrm{f}$. sp. tritici detection by qRT-PCR was still $>80 \%$. GLMM indicated that the incidence of overall (both leaf and sheath) positive qRT-PCR results increased with increasing altitude $(P=0.04)$. Once the altitude effect was accounted for, there were no longer significant differences between sites. There was some evidence for differential incidences of positive PCR results between leaf and sheath samples at Gangu A $(P=0.08)$ and Guide $(P=0.07)$. At both sites, more leaf samples had positive $P$. striiformis f. sp. tritici results than for sheath. When 
data were analyzed separately for leaves and sheath, altitude did not significantly affect the incidence of $P$. striiformis $\mathrm{f}$. sp. tritici in leaves but was positively $(P<0.05)$ correlated with the incidence of $P$. striiformis f. sp. tritici in sheath. For leaves, the site effects were large $(P<0.001)$, with the highest incidence from Qinzhou B and C; for sheath, the differences among sites were also significant $(P<0.05)$, with the highest from Qinzhou C and Zhuanglang B.

Samples from Guide and Qinzhou B had the lowest incidence of positive qRT-PCR results, and the highest incidence was from Jianzha and Xunhua. Incidence of positive qRT-PCR detection was least for the SO treatment (78\%) compared with 92 to $93 \%$ for the other two treatments. The incidence of $P$. striiformis $\mathrm{f}$. sp. tritici detected by qRT-PCR was very high in 2013-14, with all samples greater than $60 \%$ (100\% for five treatments; Table 2$)$. The effect of altitude was not significant but the effects of both sites $(P<0.001)$ and tissue types $(P<0.001)$ as well as their interactions $(P<0.01)$ were all significant. However, because of collinearity (due to $100 \%$ incidence or close to $100 \%$ for many treatment combinations), many variance estimates for treatment effects were seriously inflated, resulting in difficulties in conducting individual pairwise comparisons. Interactions between sites and tissue types were due to (i) higher incidence for the WP treatment at Jianzha, Qinzhou C, and Xunhua and (ii) higher
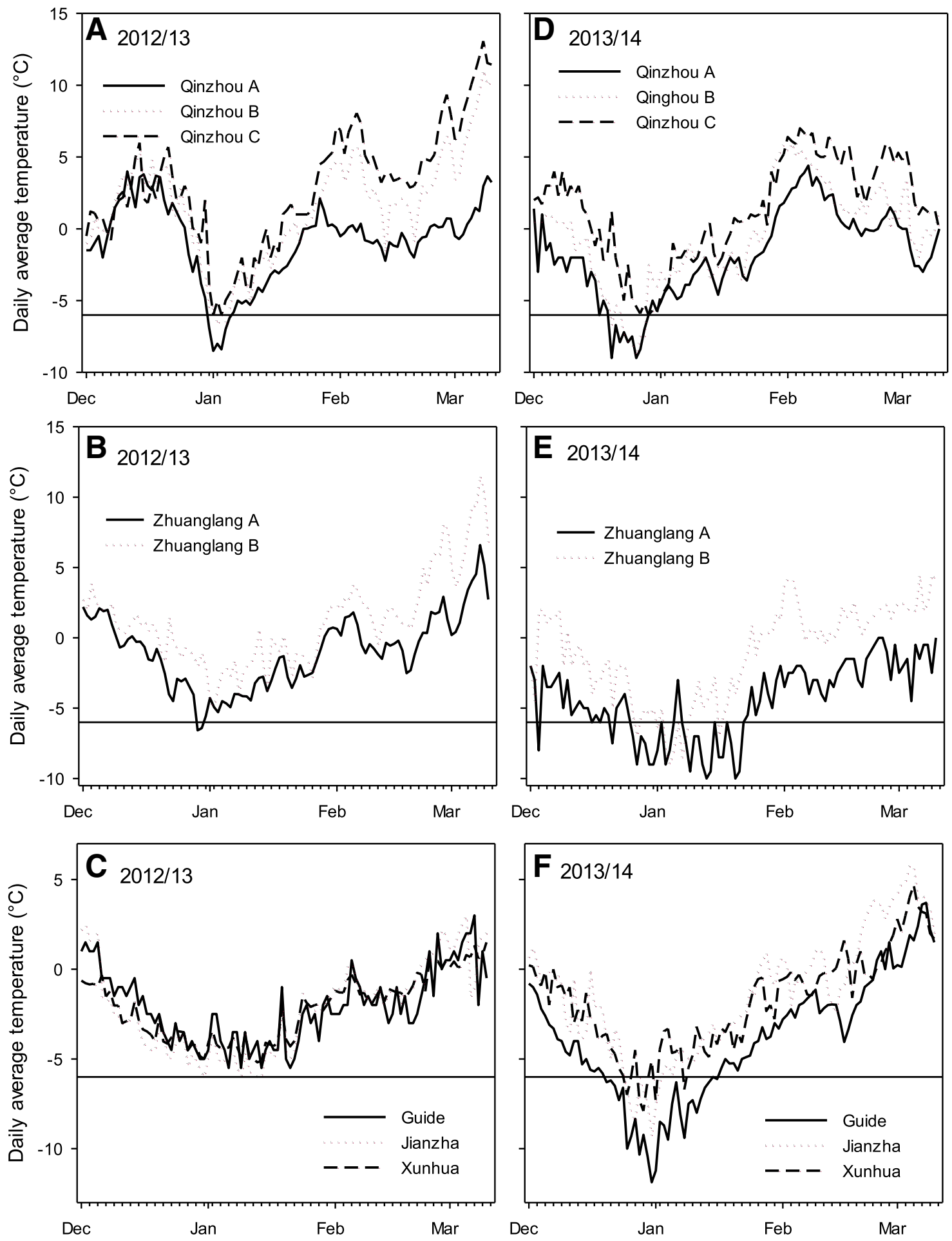

Fig. 2. Daily average temperatures from 1 December to 10 March in 2012-13 (A-C) and 2013-14 (D-F) at each sampling location. Temperature for the two Gangu sites was not available. Temperature was recorded at each site with a logger (USB502) at hourly intervals. 
incidence for the YLO treatment at Qinzhou A and Zhuanglang A and B (Table 2).

Urediniospore numbers in samples estimated with qRT-PCR. The estimated number of $P$. striiformis $\mathrm{f}$. sp. tritici urediniospores via the qRT-PCR method varied greatly among individual samples within the same treatment and among treatments. Because of extremely skewed distributions, Figure 3 presents the median numbers of urediniospores instead of arithmetic means of those samples with estimated number of urediniospores $\geq 0.5$. Only a few samples in 2012-13 did not show positive qRT-PCR results for $P$. striiformis f. sp. tritici with large $\mathrm{Cq}$ values ( $>34)$. The estimated number of urediniospores was $<0.5$.

For 2012-13, all median numbers of urediniospores were $<10$, except for the sheath samples at Xunhua, with a median value of 21 (Fig. 3A). Linear mixed-model analysis showed that there were significant differences in the estimated number of urediniospores among sites $(P<0.01)$, and the interaction between tissue types (leaf or sheath) and sites was close to statistical significance $(P=0.053)$. Samples from Guide and Qinzhou A had the least number of urediniospores and samples from Jianzha and Qinzhou B had the greatest number of urediniospores. The interaction between sites and tissue types resulted primarily from the fact that fewer urediniospores were estimated in the sheath relative to the leaves at Gangu B and Qinzhou $\mathrm{C}$ and the opposite was true for Guide, Qinzhou A, Xunhua, and Zhuanglang A (Fig. 3A).

Estimated number of $P$. striiformis $\mathrm{f}$. sp. tritici urediniospores was much greater in 2013-14 than in 2012-13 (Fig. 3); the difference was about three- to fourfold. The highest median value was approximately 71 urediniospores for the WP at Qinzhou C (Fig. 3B). Estimated number of urediniospores decreased $(P<0.001)$ with increasing altitude. There were significant differences in the estimated number of urediniospores among sites $(P<0.001)$, and the interaction

Table 2. Percentage of wheat plants or tissues with positive quantitative reverse-transcription polymerase chain reaction (qRT-PCR) results, with Puccinia striiformis f. tritici sporulation (Spor.), or with P. striiformis f. sp. tritici symptom without sporulation (PSWS) ${ }^{\mathrm{x}}$

\begin{tabular}{|c|c|c|c|c|c|c|c|c|c|c|c|c|c|}
\hline \multirow[b]{3}{*}{ Site } & \multicolumn{6}{|c|}{ 2012-13 } & \multicolumn{7}{|c|}{$2013-14^{y}$} \\
\hline & \multicolumn{4}{|c|}{ qRT-PCR } & \multirow[b]{2}{*}{ PSWS $^{\mathbf{z}}$} & \multirow[b]{2}{*}{ Spor. $^{\mathrm{z}}$} & \multicolumn{3}{|c|}{ YLO } & \multicolumn{3}{|c|}{ WP } & \multirow{2}{*}{$\frac{\text { SO }}{\text { qRT-PCR }}$} \\
\hline & None & Leaf & Sheath & Both & & & qRT-PCR & PSWS & Spor. & qRT-PCR & PSWS & Spor. & \\
\hline Gangu A & 10.0 & 43.3 & 3.3 & 43.3 & $33.3 \mathrm{ab}$ & $12.5 \mathrm{a}$ & NG & NG & NG & NG & NG & NG & NG \\
\hline Gangu B & 17.5 & 25.0 & 27.5 & 30.0 & $43.8 \mathrm{ab}$ & $29.2 \mathrm{a}$ & NG & NG & NG & NG & NG & NG & NG \\
\hline Qinzhou A & 13.7 & 22.2 & 30.8 & 33.3 & $31.3 \mathrm{ab}$ & $18.8 \mathrm{a}$ & 100.0 & 25.0 & 8.3 & 91.7 & 33.3 & 18.8 & 66.7 \\
\hline Qinzhou B & 0.0 & 3.5 & 0.0 & 96.5 & $43.8 \mathrm{bc}$ & $31.3 \mathrm{~b}$ & 83.3 & 29.2 & 18.8 & 91.7 & 41.7 & 31.3 & 60.4 \\
\hline Qinzhou C & 0.9 & 1.7 & 5.1 & 92.3 & $58.3 \mathrm{c}$ & $50.0 \mathrm{~b}$ & 91.7 & 33.3 & 18.8 & 100.0 & 43.8 & 33.3 & 60.4 \\
\hline Zhuanglang A & 2.5 & 6.7 & 23.3 & 67.5 & $27.1 \mathrm{a}$ & $8.3 \mathrm{a}$ & 100.0 & 10.4 & 4.2 & 83.3 & 16.7 & 4.2 & 83.3 \\
\hline Zhuanglang B & 0.0 & 0.0 & 5.0 & 95.0 & $25.0 \mathrm{a}$ & $16.7 \mathrm{a}$ & 100.0 & 16.7 & 6.3 & 93.8 & 20.8 & 12.5 & 75.0 \\
\hline Guide & 0.0 & 20.2 & 13.2 & 66.7 & $18.8 \mathrm{a}$ & $2.1 \mathrm{a}$ & 87.5 & 6.3 & 0.0 & 75.0 & 10.4 & 0.0 & 87.5 \\
\hline Jianzha & 0.0 & 0.0 & 0.0 & 100.0 & $20.8 \mathrm{a}$ & $4.2 \mathrm{a}$ & 91.7 & 16.7 & 10.4 & 100.0 & 16.7 & 4.2 & 93.4 \\
\hline Xunhua & 2.5 & 6.7 & 27.5 & 63.3 & $22.9 \mathrm{a}$ & $8.3 \mathrm{a}$ & 87.5 & 16.7 & 6.3 & 100.0 & 29.2 & 10.4 & 93.8 \\
\hline
\end{tabular}

${ }^{x}$ Plants with $P$. striiformis f. sp. tritici symptoms were tagged in late November and dug up in early March of the following year. There were 30 (2012-13) or 36 (2013-14) plants for each of the four varieties at each site. The number of sampled plants was 120 for 2012-13 but, for a few samples, qRT-PCR failed; there were 48 plants for each tissue type in 2013-14.

y $\mathrm{YLO}=$ young leaves only (the two outmost leaves with $P$. striiformis $\mathrm{f}$. sp. tritici symptoms were removed), $\mathrm{WP}=$ whole plant, $\mathrm{SO}=$ sheath only (all other leaves were cut off), and $\mathrm{NG}=$ not grown.

${ }^{\mathrm{z}}$ Letters following numbers indicate the results of multiple pairwise comparisons based on the least significant difference test at $P=0.05$, with the mean and standard error of differences from a generalized linear mixed-model analysis of count data (assuming a binomial distribution for residuals). The linear effects of altitude were removed first, before the site factor was introduced. Any two sites showing at least one common letter did not differ significantly. For 2013-14, there were significant differences among sites once the linear altitude effects were accounted for.

A

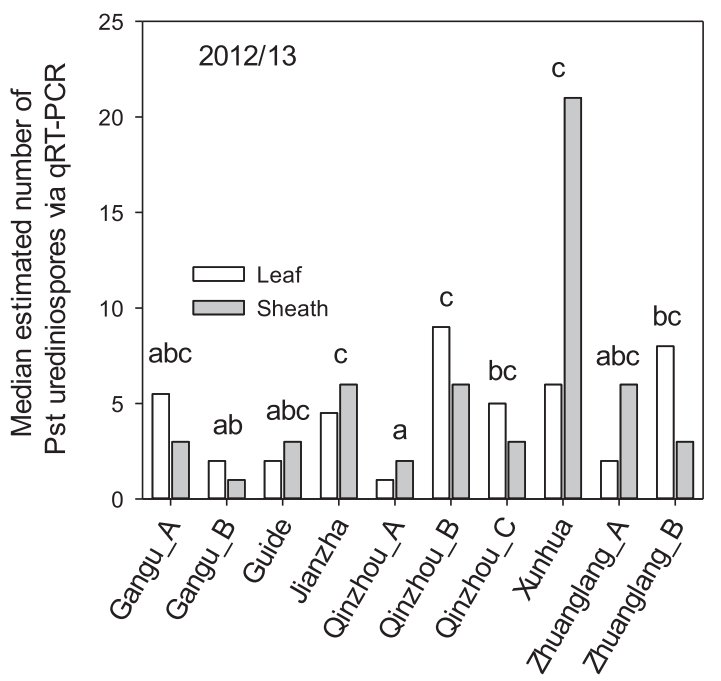

B

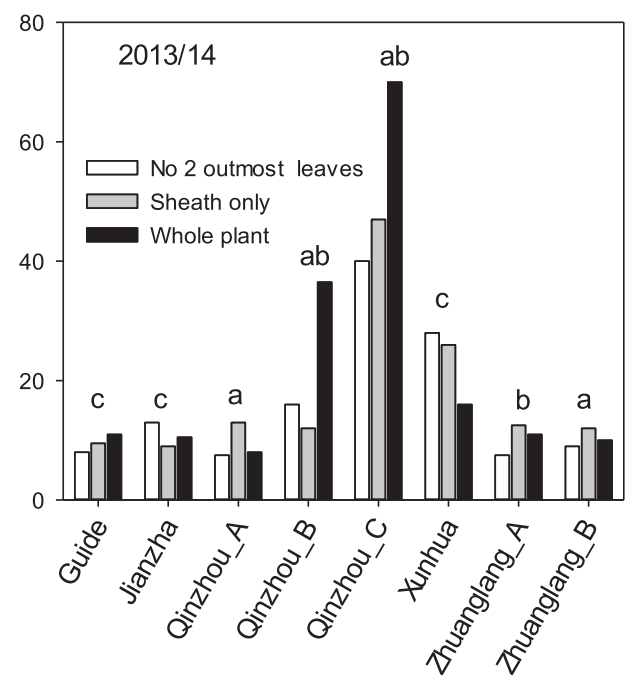

Fig. 3. Median number of estimated Puccinia striiformis f. tritici urediniospores via a quantitative reverse-transcription polymerase chain reaction (qRT-PCR) method in 2012-13 (A) and 2013-14 (B). Median was calculated only from those samples with positive qRT-PCR (i.e., estimated number of urediniospores $\geq 0.5$ ). Letters above each site were the results of multiple pairwise comparisons based on the least significant difference test at $P=0.05$ with the mean and standard error of differences from mixed-model analysis of In-transformed number of urediniospores. Any two sites containing at least one common letter did not differ significantly. 
between tissue types and sites was also highly significant $(P<0.001)$. After the altitude effect was removed, the eight sites can be divided into two groups: (i) three sites in Qinghai and (ii) the other five sites. Samples from Qinghai had more urediniospores than from the other sites. The interaction between sites and tissue types resulted mainly from the following differences: (i) for Jianzha and Xunhua, the YLO treatment had greater $P$. striiformis $\mathrm{f}$. sp. tritici biomass than the other two treatments, and (ii) for Qinzhou B, lowest number of $P$. striiformis f. sp. tritici urediniospores was estimated for the SO treatment.

The linear mixed modeling indicated that the overall variety effect is relative small; its variance component size was approximately 5 to $20 \%$ of the estimated residual variance in both years. The overall effects of sites and tissue types were consistent over the two common varieties in both years (Fig. 4). There was only one noticeable difference: the estimated number of $P$. striiformis $\mathrm{f}$. sp. tritici urediniospores was greater on XN979 than on XY22 in the WP treatment relative to the other two treatments at Qinzhou C (Fig. 4).

Incidence of overwintered plants with $\boldsymbol{P}$. striiformis f. sp. tritici symptoms and sporulation. In 2012-13, the incidence of plants with $P$. striiformis f. sp. tritici uredinia after incubation for 1 to 2 weeks decreased $(P<0.001)$ with increasing altitude and also differed $(P<0.05)$ among sites, ranging from $19 \%$ at Guide to $58 \%$ at Qinzhou C. The incidence at Guide, Jianzha, Xunhua, and Zhuanglang A was among the lowest; it was the highest for samples from Qinzhou C (Table 2). Fewer samples had sporulating lesions than with visible $P$. striiformis $\mathrm{f}$. sp. tritici symptoms after incubation, ranging from $2.1 \%$ at Guide to $50.0 \%$ at Qinzhou C (Table 2). Similarly, the incidence of samples with active sporulation decreased $(P<0.001)$ with increasing altitude and differed

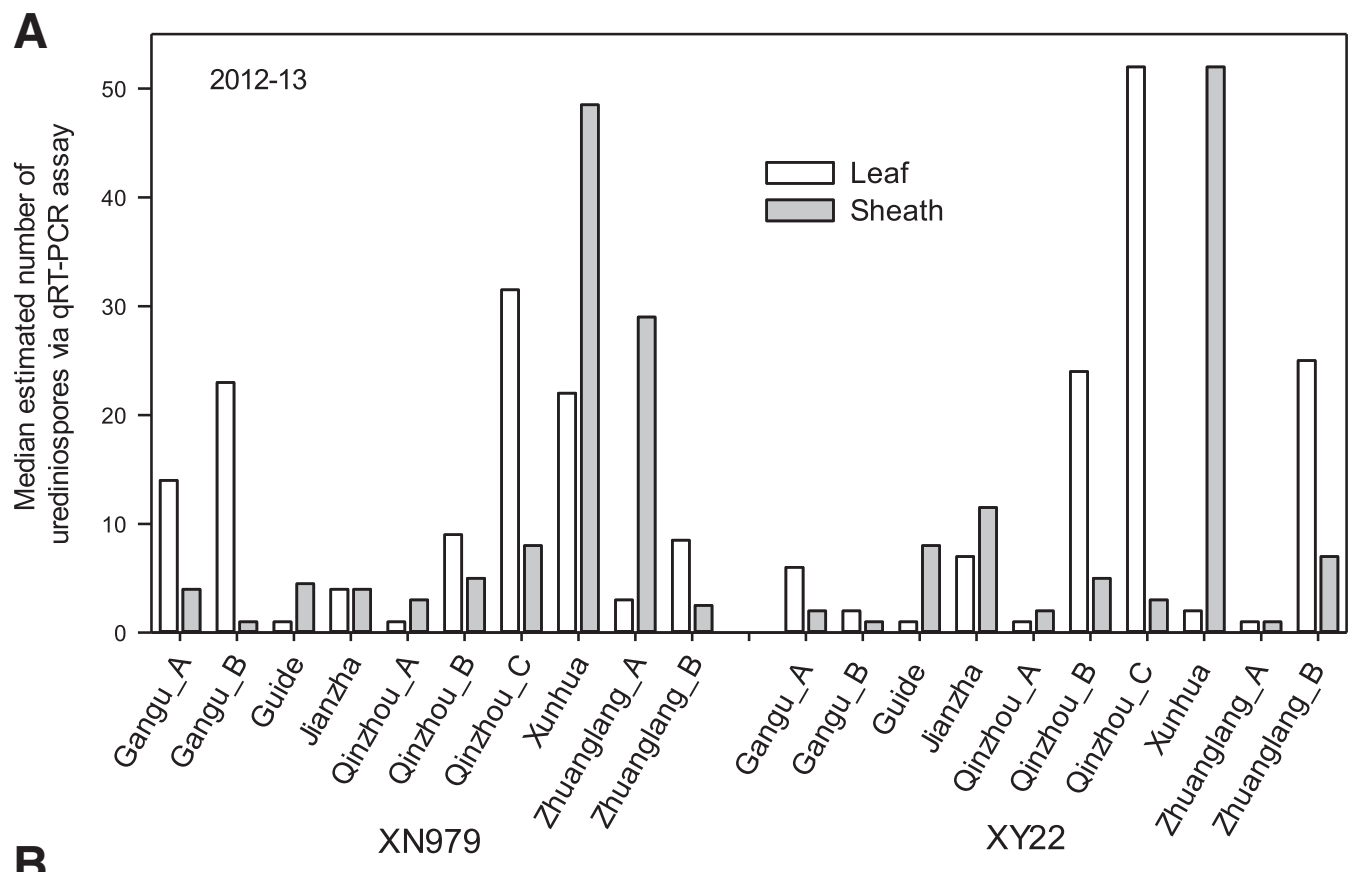

B

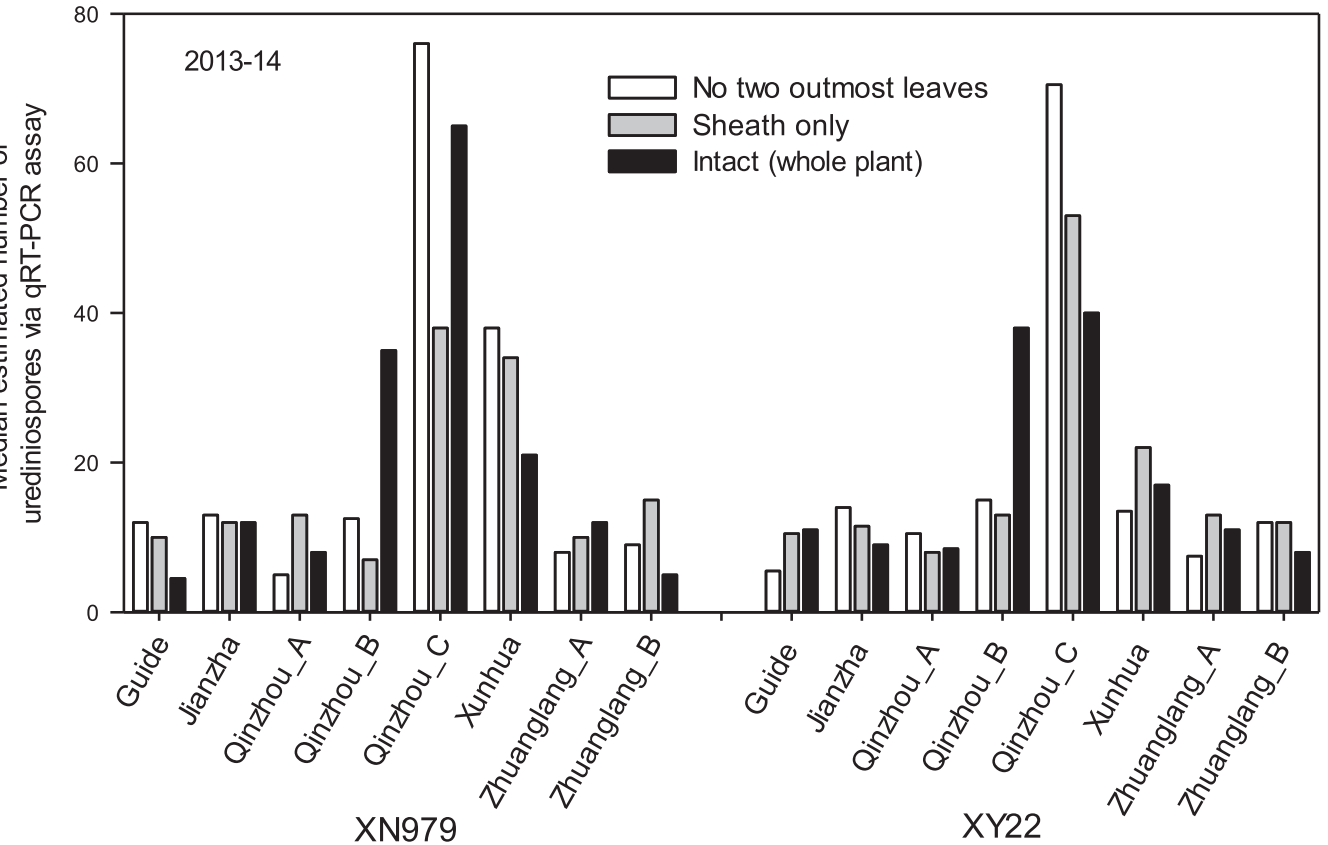

Fig. 4. Median number of estimated Puccinia striiformis $\mathrm{f}$. tritici urediniospores via a quantitative reverse-transcription polymerase chain reaction (qRT-PCR) method on two common varieties (XN979 and XY22) across all sites in 2012-13 (A) and 2013-14 (B). Median was calculated only from those samples with positive qRT-PCR (i.e., estimated number of urediniospores $\geq 0.5$ ). Plants with $P$. striiformis $\mathrm{f}$. $\mathrm{sp}$. tritici uredinia were tagged in late November and dug up in early March of the following year. 
$(P<0.05)$ among sites as well. Once the altitude effect was accounted for, Qinzhou B and C had the highest incidence of sporulation.

In 2013-14, the incidence of plants with $P$. striiformis f. sp. tritici symptoms after incubation varied greatly among sites, ranging from $8.4 \%$ at Guide to $38.6 \%$ at Qinzhou C. Increasing altitude led to reduced $(P<0.001)$ incidence of sporulation. Once the altitude effect was accounted for, differences between sites were no longer statistically significant. Incidence of plants with $P$. striiformis f. sp. tritici symptoms was greater $(P<0.05)$ on the WP treatment $(27 \%)$ than on the YLO treatment (19\%). There were no significant interactions between sites and tissue types. No sporulation was observed on samples from Guide and, for the remaining sites, the incidence ranged from $4.2 \%$ at Zhuanglang $A$ to $26.1 \%$ at Qinzhou C. The incidence of sporulation decreased $(P<0.001)$ with increasing altitude. The difference between the WP and YLO treatments was close to statistical significance $(P=0.06): 14.3$ and $9.1 \%$ of samples had sporulation lesions after incubation for the WP and YLO treatments, respectively.

\section{Discussion}

The amount of $P$. striiformis $\mathrm{f}$. sp. tritici in tissues can be quantified using real-time qPCR of DNA (Yan et al. 2012). However, RNA is expected to be a better choice over DNA as an indicator of metabolic changes in response to external factors and indicating the viability. Quantification of RNA using qRT-PCR has recently been developed and used for plant pathogens, including Verticillium dahliae (Tran et al. 2014), V. longisporum (Tran et al. 2014), Pectobacterium atrosepticum (Takle et al. 2007), Puccinia triticina (Bruce et al. 2014; Scholtz and Visser 2013), and P. striiformis f. sp. tritici (Ma et al. 2015; Tang et al. 2013).

$P$. striiformis f. sp. tritici was detected in early spring in both leaves and sheaths at all sited studies via a qRT-PCR method. Active sporulation on those overwintered plants was observed for all sites except one. A large proportion of differences in P. striiformis f. sp. tritici overwintering potentials among sites can be accounted for by the differences in altitude; increasing altitude generally led to decreased $P$. striiformis f. sp. tritici overwintering potential.

The fresh urediniospores (like plasmid) were used to construct a standard curve instead of germinated urediniospores, because the percentage of $P$. striiformis $\mathrm{f}$. sp. tritici urediniospore germination varied from 40 to $85 \%$ and it was difficult to control to the same germination rate between experiments. The log transformation of urediniospore number had a good linear relationship with the $\mathrm{Cq}$ value of qRT-PCR $\left(R^{2}>0.99\right)$.

The qRT-PCR method detected $P$. striiformis f. sp. tritici in leaves and sheaths in most plants sampled from all sites in early March. On those plants (tissues) with positive qRT-PCR results, there were significant differences in the estimated numbers of urediniospores between sites and the interaction between sites and plant tissues. However, there were no clear patterns in these differences except that, in both years, the highest numbers of urediniospores were predicted for Xunhua and Qinzhou B and C. The incidence of plants (tissues) with positive qRT-PCR results was much greater than the incidence of plants showing visual P. striiformis f. sp. tritici active sporulation after incubation. Sampling errors and differences between two parts of the plant used for PCR and incubation are unlikely to cause such unidirectional differences in favor of qRT-PCR. A more probable cause is that the qRT-PCR method is too sensitive as used in the present study; namely, the threshold of 0.5 urediniospores as evidence for $P$. striiformis $\mathrm{f}$. sp. tritici presence is probably too low. Unfortunately, we only counted the total number of plants with $P$. striiformis $\mathrm{f}$. sp. tritici sporulation but did not record individual plants separately. Thus, we could not relate the estimated number of urediniospores to the sporulation and, hence, cannot relate the qRT-PCR results to $P$. striiformis $\mathrm{f}$. sp. tritici sporulation on individual plants. Another reason is that not all detected $P$. striiformis $\mathrm{f}$. sp. tritici would lead to visible sporulation and, thus, the incidence of positive PCR detection is expected to be the maximum incidence of sporulating $P$. striiformis f. sp. tritici. Interestingly, unlike for incidence of sporulating $P$. striiformis f. sp. tritici lesions, the effects of altitude on the incidence of positive PCR results and on the estimated number of urediniospores were inconsistent between the 2 years.

There were large differences in the incidence of visible and sporulating $P$. striiformis f. sp. tritici symptoms between sites on different tissue types (treatments). From the epidemiological point of view, the key is that overwintered $P$. striiformis f. sp. tritici has to produce urediniospores to initiate new infections in spring. Based on this criterion, we can exclude sheath as an important overwintering tissue because none of plants from the SO treatment led to sporulating lesions on green leaves across all sites, even though there were higher incidences of qRT-PCR-positive results for $P$. striiformis f. sp. tritici in sheaths. Given that $P$. striiformis f. sp. tritici is an obligate pathogen, it requires actively growing green tissue to support sporulation. When all green leaves were cut off in late November, new leaves would emerge slowly because of the low temperatures at that time. Thus, the chance for $P$. striiformis f. sp. tritici to infect the newly emerged leaves would be very small because of the cold temperatures during that time, much lower than that required for $P$. striiformis $\mathrm{f}$. $\mathrm{sp}$. tritici to infect. For the same reason (also, lack of spores), leaves emerged in early spring were not likely to be infected either before being taken to laboratory. Thus, we may conclude that $P$. striiformis $\mathrm{f}$. sp. tritici overwintering is unlikely for those areas where all green leaves do not survive the winter. These results indicated that latent infection in the young leaves that had established in late autumn to early winter is the main source of $P$. striiformis $\mathrm{f}$. sp. tritici overwintering inoculum, consistent with previous findings based on field observations (Li and Zeng 2002). P. striiformis f. sp. tritici may remain latent for nearly 100 days as dormant mycelia or uredia (Cohen et al. 2013). $P$. striiformis f. sp. tritici was not able to overwinter on the outmost two leaves (with most $P$. striiformis f. sp. tritici symptoms in autumn) because they died during the winter. Nevertheless, the present study suggested that the old leaves may protect $P$. striiformis $\mathrm{f}$. sp. tritici inside young leaves and, hence, removing them may lead to reduced $P$. striiformis f. sp. tritici overwintering potentials.

For both visible and sporulating $P$. striiformis f. sp. tritici lesions, samples from higher altitudes generally had reduced incidence when assessed in early spring. This altitude effect on $P$. striiformis f. sp. tritici overwintering potential was also recently observed in field studies (Pan et al. 2011; Yao et al. 2014). It may be attributed to the fact that air temperature decreases with increasing altitude (Fig. 2). However, this is unlikely to be the only explanation. For example, only $2 \%$ of samples from Guide had sporulation in 2012-13, compared with the $8 \%$ observed at Zhuanglang A site in 2013-14, where the temperature was at least $3{ }^{\circ} \mathrm{C}$ lower than at Guide in 2012-13 during January. One probable explanation is the wind-chill factor (perceived decrease in air temperature felt by the body on exposed surface due to the flow of air). At high altitudes, sites tended to be more exposed and, hence, experienced more windy conditions than at lower-altitude sites. During the winter, this may lead to windchill effects that are not captured by temperature; this additional "chilling" may reduce $P$. striiformis f. sp. tritici overwintering potentials. On the other hand, snow cover may increase $P$. striiformis f. sp. tritici overwinter potentials. Thus, using temperature only to predict the overwintering potential of $P$. striiformis f. sp. tritici in mountainous regions may lead to considerable errors.

The low temperature limit of air temperature for $P$. striiformis $\mathrm{f}$. $\mathrm{sp}$. tritici overwintering (November to February in China) is believed to be around -6 to $-7^{\circ} \mathrm{C}$ (monthly mean) (Li and Zeng 2002; Zeng and Luo 2006) and could be as low as $-10^{\circ} \mathrm{C}$ when wheat plants are under snow. In the present study, we placed temperature loggers at the experimental site among the plants. Thus, whether they were under snow or not, the temperatures recorded should be close to what the plants experienced. At Zhuanglang A site, average temperature over a 30-day period was $<-6^{\circ} \mathrm{C}$ for 30 days and $<-7^{\circ} \mathrm{C}$ for 13 days in 2013-14. Nevertheless, there were at least $4 \%$ of plants from this site showing sporulation after incubation in early spring. This may suggest that $P$. striiformis f. sp. tritici could survive for longer or at even lower temperatures than previously thought. Indeed, recently, we reported that $P$. striiformis f. sp. tritici can survive for $12 \mathrm{~h}$ at -15 to $-20^{\circ} \mathrm{C}$ 
(Ma et al. 2015). Numbers of samples with $P$. striiformis f. sp. tritici sporulation decreased with the increasing altitude in the same region; for instance,18.8, 31.3, and 50.0\% in Qinzhou A (1,731 m), Qinzhou B $(1,644 \mathrm{~m})$, and Qinzhou C $(1,590)$ in 2012-13, and 18.8, 31.3, and $33.3 \%$ in $2013-14$, respectively. Given the anticipated climate change (Fang et al. 2012) and the effect of altitude on P. striiformis f. sp. tritici overwintering, the regional profile of $P$. striiformis f. sp. tritici overwintering risks should be regularly updated. This need is demonstrated by the present study, which shows that $P$. striiformis f. sp. tritici can overwinter at 9 of 10 sites that are currently classified as nonoverwintering regions (Shen and Wang 1962; Shi et al. 2005).

Varieties differ in their winter hardiness and, hence, may affect $P$. striiformis f. sp. tritici overwintering potential indirectly through their differences in whether green leaves would survive the winter. It was not possible to have the same varieties across all sites. Moreover, because of few sampling units and lower $P$. striiformis f. sp. tritici incidence in 2013-14, including variety as a fixed factor will lead to statistical analysis of reduced sensitivities. Treating variety as a random effect factor should lead to more conservative and, hence, more reliable conclusions. It should be noted that, when the data were restricted to the two common varieties, the overall conclusions remained the same and the contribution of the variety to the observed variation was small relative to altitude, site, and tissue type (results not shown). Similarly, a previous study showed that there were only small differences in $P$. striiformis f. sp. tritici survival over the winter among different wheat varieties in the same region (Pan et al. 2011).

In summary, we found that $P$. striiformis f. sp. tritici is able to overwinter in regions where it was previously thought it could not, expanding the overwintering regions. Further research is necessary to refine the current qRT-PCR method for estimating potential risks of latent infections of $P$. striiformis $\mathrm{f}$. sp. tritici in green leaves. Otherwise, using the method may overestimate $P$. striiformis f. sp. tritici overwintering potentials. Young leaves with latent infections of $P$. striiformis f. sp. tritici are the main tissues on which P. striiformis f. sp. tritici overwinters. In predicting overwintering potential for a given site, we need to consider factors such as altitude, snow cover, and wind chill in addition to temperature.

\section{Acknowledgments}

We thank X. Chen (United States Department of Agriculture and Department of Plant Pathology, Washington State University) for his kind suggestions. This work was supported by the National Key Basic Research Program of China (2013CB127700) and the National Natural Science Foundation of China (31071640 and 31271985), and partially supported by the 111 Project from Education Ministry of China (B07049)

\section{Literature Cited}

Bruce, M., Neugebauer, K. A., Joly, D. L., Migeon, P., Cuomo, C. A., Wang, S. C., Akhunov, V., Bakkeren, G., Kolmer, J. A., and Fellers, J. P. 2014. Using transcription of six Puccinia triticina races to identify the effective secretome during infection of wheat. Front. Plant Sci. 4:520.

Burleigh, J. R. 1965. The Winter Biology of Puccinia striiformis West. in the Pacific Northwest. Washington State University, Pullman.

Chen, X. 2005. Epidemiology and control of stripe rust on wheat (Puccinia striiformis f. sp. tritici] on wheat. Can. J. Plant Pathol. 27:314-337.
Cohen, R., Anikster, Y., Vintal, H., Manisterski, J., and Shtienberg, D. 2013. Overwintering and epidemiology of Puccinia dracunculina, the causal agent of rust in open tarragon fields. Plant Pathol. 62:41-48.

Fang, S., Tan, K., Ren, S., Zhang, X., and Zhao, J. 2012. Fields experiments in North China show no decrease in winter wheat yields with night temperature increased by $2.0-2.5^{\circ} \mathrm{C}$. Sci. China Earth Sci. 55:1021-1027.

Gladders, P., Langton, S. D., Barrie, I. A., Hardwick, N. V., Taylor, M. C., and Paveley, N. D. 2007. The importance of weather and agronomic factors for the overwinter survival of yellow rust (Puccinia striiformis) and subsequent disease risk in commercial wheat crops in England. Ann. Appl. Biol. 150: 371-382.

Li, Z. Q., and Shang, H. S. 1989. Wheat Rusts and Their Control. Shanghai Science and Technology Press, Shanghai, China.

Li, Z. Q., and Zeng, S. M. 2002. Wheat Rust in China. China Agricultural Press, Beijing.

Ma, L., Qiao, J., Kong, X., Zou, Y., Xu, X., Chen, X., and Hu, X. 2015. Effect of low temperature and wheat winter-hardiness on survival of Puccinia striiformis f. sp. tritici under controlled conditions. PLoS One 10:e0130691.

Pan, G., Chen, W. Q., Liu, T. G., Gao, L., Cao, S. Q., and Wang, X. M. 2011. Survey of overwintering Puccinia striiformis f. sp. tritici at different altitudes in the areas of Tianshui, Gansu province. Plant Prot. Chin. 37:103-106.

Scholtz, J. J., and Visser, B. 2013. Reference gene selection for qPCR gene expression analysis of rust-infected wheat. Physiol. Mol. Plant Pathol. 81:22-25.

Sharma-Poudyal, D., and Chen, X. M. 2011. Models for predicting potential yield loss of wheat caused by stripe rust in the U.S. Pacific Northwest. Phytopathology 101:544-554.

Sharp, E. L., and Hehn, E. R. 1963. Overwintering of stripe rust in winter wheat in Montana. Phytopathology 53:1239-1240.

Shen, Q. Y., and Wang, K. N. 1962. Research status and future directions on epidemiology of wheat stripe rust in China. Acta Phytophylac. Sin. Chin. 1: 393-402.

Shi, S. D., Ma, Z. H., Wang, H. G., Zhao, Z. H., and Jiang, Y. Y. 2005. Climatebased regional classification for overwintering of Puccinia striiformis in China with GIS and geostatistics. Acta Phytophylac. Sin. Chin. 32:29-32.

Stubbs, R. 1988. Pathogenicity Analysis of Yellow (Stripe) Rust of Wheat and Its Significance in a Global Context. In: Breeding Strategies for Resistance to the Rust of Wheat. N. W. Simmonds and S. Rajaram, eds. CIMMYT, Texcoco, Mexico.

Takle, G. W., Toth, I. K., and Brurberg, M. B. 2007. Evaluation of reference genes for real-time RT-PCR expression studies in the plant pathogen Pectobacterium atrosepticum. BMC Plant Biol. 7:50.

Tang, C. L., Wang, X. J., Duan, X. Y., Wang, X. D., Huang, L. L., and Kang, Z. S. 2013. Functions of the lethal leaf-spot 1 gene in wheat cell death and disease tolerance to Puccinia striiformis. J. Exp. Bot. 64:2955-2969.

Tran, V. T., Braus-Stromeyer, S. A., Kusch, H., Reusche, M., Kaever, A., and Kuhn, A. 2014. Verticillium transcription activator of adhesion Vta2 suppresses microsclerotia formation and is required for systemic infection of plant roots. New Phytol. 202:565-581.

Wan, A. M., Zhao, Z. H., and Wu, L. R. 2003. Reviews of occurrence of wheat stripe rust disease in 2002 in China. Plant Prot. Chin. 29:5-8.

Yan, J. H., Luo, Y., Chen, T. T., Huang, C., and Ma, Z. H. 2012. Field distribution of wheat stripe rust latent infection using real-time PCR. Plant Dis. 96:544-551.

Yao, Q., Guo, Q. Y., Yan, J. H., Zhang, G., Hou, S. Y., and Chen, W. Q. 2014. Survey on overwintering Puccinia striiformis f. sp. tritici at different altitudes in eastern Qinghai. Acta Phytophylac. Sin. 41:573-578.

Yin, C., Chen, X., Wang, X., Han, Q., Kang, Z., and Hulbert, S. H. 2009. Generation and analysis of expression sequence tags from haustoria of the wheat stripe rust fungus Puccinia striiformis f. sp. Tritici. BMC Genomics 10:626.

Zeng, S.-M., and Luo, Y. 2006. Long-distance spread and interregional epidemics of wheat stripe rust in China. Plant Dis. 90:980-988.

Zeng, S. M., and Luo, Y. 2008. Systems analysis of wheat stripe rust epidemics in China. Eur. J. Plant Pathol. 121:425-438. 